\title{
The Effect of Geonet Reinforcement on Bearing Capacity of Low-Compacted Soft Clay
}

\author{
Mohammed O. A. Bazne • Farshid Vahedifard • \\ Shahriar Shahrokhabadi
}

Accepted: 4 December 2014 / Published online: 24 December 2014

(C) Springer New York 2014

\begin{abstract}
In this paper, we studied if geonets, when used for drainage purposes, can also contribute to the bearing capacity of clay. For this purpose, extensive laboratory testing and numerical modeling were performed on various configurations to investigate the effect of geonet on the bearing capacity of low-compacted soft clay. Physical models built with four footing shapes (square, rectangular, and two circular) along with several configurations of the reinforcement layout (i.e., number, length, spacing, and depth of reinforcement layers) were tested in the laboratory. Moreover, finite element modeling was performed and the results were compared with those obtained from the laboratory tests. It was found the geonet reinforcement can improve the bearing capacity of low-compacted clay up to six times more than its natural condition. The results showed that the optimum reinforcement length for the single-layer model is $3 B$ (where $B$ is the width of footing) and beyond this length, no significant improvement was observed. However, for the two-layer and three-layer models, the optimum length of reinforcements was found to be $2 B$. To maximize the benefit of the reinforcement, it was found that the first, second, and third reinforcement layers should be placed at the depths of $B / 3, B / 2$, and $B$, respectively. Among different footing shapes which were tested, the square footing showed the highest bearing capacity improvement with a bearing capacity ratio of 7.6. Very good agreement was observed upon comparison of the results from the numerical modeling with the experimental tests.
\end{abstract}

Keywords Geonet $\cdot$ Soft soil $\cdot$ Bearing capacity $\cdot$ Reinforcement $\cdot$ Numerical modeling

\footnotetext{
M. O. A. Bazne $\cdot$ F. Vahedifard $(\bowtie) \cdot$ S. Shahrokhabadi

Department of Civil and Environmental Engineering, Mississippi State University, Mississippi State, MS 39762, USA

e-mail: farshid@cee.msstate.edu
}

M. O. A. Bazne

e-mail: mob58@msstate.edu

S. Shahrokhabadi

e-mail: ss2437@msstate.edu 


\section{Introduction}

Soft foundation soils exhibit large settlement and low shear strength imposing major limitations in construction and earth works. Replacing soft soil with high-quality fill material is commonly recommended to improve bearing capacity and to decrease settlement. Alternatively, reinforcements can be used as a remedy to improve soil characteristics. Foundation soil reinforcement with geosynthetics has been widely recognized as a technically and economically viable solution to tackle excessive settlement and low bearing capacity of soft soils, especially for shallow foundations [1-4]. Extensive experimental and numerical studies have shown that various parameters such as the type of reinforcement, layout of reinforcement, size and shape of footings, and soil and geosynthetic interface can influence the performance of the foundation soil reinforced with geosynthetics [e.g., 5-15].

Various techniques (e.g., replacement with granular soil, compaction, stone columns, pre-loading, reinforcement) can be employed to improve bearing capacity and settlement characteristics of soft soil. The effects of geosynthetic reinforcements on bearing capacity and settlement of different soil types have been extensively investigated [16-27]. In general, the majority of previous works consider a reinforced sand bed and propose to replace the soft soil with compacted sand or stabilize the soft soil with granular soils [3, 28, 29]. However, there is limited data in the literature regarding the effect of reinforcement on low-compacted soft clay. Demand for construction on fine-grained foundation soils has recently increased [29], in most cases due to lack of granular and high-quality fill at the site or within a reasonable distance. While fine-grained soils, especially clay, are not desirable for foundations, soil replacement may not be an economical solution for construction sites including a very thick layer of fine-grained soft soil. Moreover, in all of the aforementioned studies, geogrids or geotextiles were used as reinforcing elements.

\section{Scope and Objectives}

This study investigates the bearing capacity and settlement of low-compacted clayey soil with and without geonet reinforcement. For this purpose, an extensive set of experimental tests was conducted to evaluate the performance of a shallow foundation resting on soft clay. Figure 1 shows the notation used in this study. As shown, $B$ is the width of

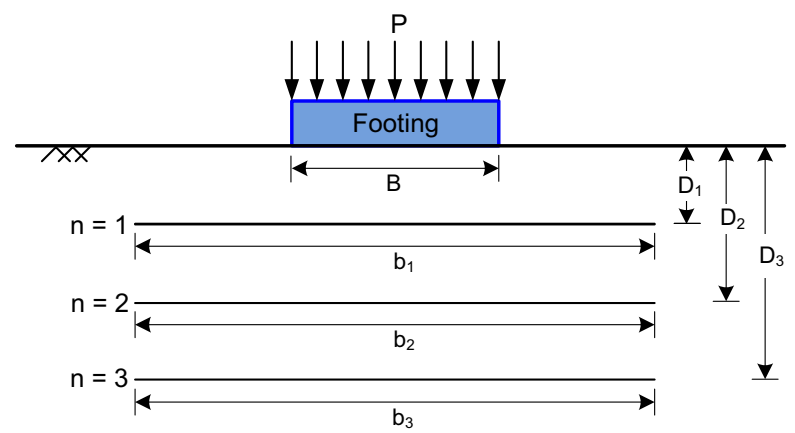

Fig. 1 Notation of variables in laboratory experiment 
footing, $b$ is the length of reinforcement layer, and $D$ is the depth of reinforcement layer. Wherever used, subscripts 1, 2, and 3 denote the first, second and third reinforcement layer from the top to bottom, respectively. Testing matrix (Table 1) was developed to experimentally perform parametric study for various combinations pertaining to the footing (shape and size) and the reinforcement (number of layers, length, depth of the first layer, and spacing). The problem was further studied by Finite Element (FE) numerical modeling of equivalent configurations using Plaxis [30]. The experimental test results were then compared to those obtained from the numerical modeling.

The focus of the current study is to study the effect of geonet reinforcement on the performance of soft clay when little or no compaction is applied. Indeed the performance of the soil foundation can further be improved by compaction. However, such low compaction was intentionally selected to mimic the in situ condition of the tested soil which was collected from a local landfill. Moreover, while other geosynthetics products such as geocell, geotextile, or geogrid are extensively used in the literature, limited data exists to demonstrate the effect of using geonet as reinforcing element. Geonets are commonly used to facilitate drainage of low-permeable soils (e.g., clay) for various geotechnical and geoenvironmental engineering applications. So, they are not primarily designated to be used as primary reinforcing element. However, this study intends to investigate if geonet, when used for drained purposes, can also contribute to the bearing capacity of the clayey soil.

\section{Experimental Testing}

\section{Materials}

\section{Soil}

Soft clayey soil with low plasticity (CL) was used in the experimental tests. The foundation soil was collected from the depth of 0.6 to $1.0 \mathrm{~m}$ from a local landfill, Zanko landfill, and exhibited high settlement and low shear strength. The soil's index and chemical properties were measured by performing pertinent standard tests on multiple replicates for each parameter of interest.

A vane shear device was used to measure the undrained shear strength of the soil after the soil layers were placed in the testing container. The average shear strength measured by the vane device was $12 \mathrm{kPa}$. Since the focus of this work was to measure the relative improvement of bearing capacity by using geonets, the accuracy of shear strength measured by the vane shear device is acceptable for the purposes of this study. The shear strength parameters and elasticity modulus were assumed based on the results from the vane shear device as well as the values reported in the literature for soft clay. Table 2 shows the deduced properties of the soil tested in the laboratory. These parameters were used for numerical simulation purposes. As shown, the soil has very low modulus of elasticity and shear strength.

\section{Geonet}

Geonet CE 750 was used as reinforcing element to improve the performance of the foundation soil. Table 3 shows properties of the geonet used in this study. The 
Table 1 Testing matrix including various configurations for the shape and width of footing $(B)$, length $(b)$, and depth of reinforcement $(D)$

\begin{tabular}{|c|c|c|c|c|c|c|c|c|c|}
\hline \multirow[t]{3}{*}{ No. } & \multirow[t]{3}{*}{ Model } & \multicolumn{2}{|l|}{ Foundation } & \multicolumn{6}{|c|}{ Reinforcement } \\
\hline & & \multirow[t]{2}{*}{ Shape } & \multirow{2}{*}{$\begin{array}{l}\text { Width }(\mathrm{cm}) \\
B\end{array}$} & \multicolumn{3}{|c|}{ Depth (cm) } & \multicolumn{3}{|c|}{ Length (cm) } \\
\hline & & & & $D_{1}$ & $D_{2}$ & $D_{3}$ & $b_{1}$ & $b_{2}$ & $b_{3}$ \\
\hline 1 & Unreinforced & Circular I & 5 & N/A & & & & & \\
\hline 2 & & Circular II & 8 & N/A & & & & & \\
\hline 3 & & Square & 5 & N/A & & & & & \\
\hline 4 & & Rectangular & 10 & N/A & & & & & \\
\hline 5 & 1-layer reinforcement & Circular I & 5 & $B / 3$ & N/A & & $B$ & N/A & \\
\hline 6 & & & & & & & $2 B$ & & \\
\hline 7 & & & & & & & $3 B$ & & \\
\hline 8 & & & & & & & $4 B$ & & \\
\hline 9 & & & & $B / 2$ & & & $B$ & & \\
\hline 10 & & & & & & & $2 B$ & & \\
\hline 11 & & & & & & & $3 B$ & & \\
\hline 12 & & & & & & & $4 B$ & & \\
\hline 13 & & & & $B$ & & & $B$ & & \\
\hline 14 & & & & & & & $2 B$ & & \\
\hline 15 & & & & & & & $3 B$ & & \\
\hline 16 & & & & & & & $4 B$ & & \\
\hline 17 & & & & $1.5 B$ & & & $B$ & & \\
\hline 18 & & & & & & & $2 B$ & & \\
\hline 19 & & & & & & & $3 B$ & & \\
\hline 20 & & & & & & & $4 B$ & & \\
\hline 21 & 2-layer reinforcement & Circular I & 5 & $B / 3$ & $B / 2$ & N/A & $2 B$ & $2 B$ & N/A \\
\hline 22 & & & & & & & $3 B$ & $3 B$ & \\
\hline 23 & & & & & & & $2 B$ & $4 B$ & \\
\hline 24 & & & & & & & $3 B$ & $4 B$ & \\
\hline 25 & & & & & & & $4 B$ & $4 B$ & \\
\hline 26 & & & & & $B$ & & $2 B$ & $2 B$ & \\
\hline 27 & & & & & & & $3 B$ & $3 B$ & \\
\hline 28 & & & & & & & $2 B$ & $4 B$ & \\
\hline 29 & & & & & & & $3 B$ & $4 B$ & \\
\hline 30 & & & & & & & $4 B$ & $4 B$ & \\
\hline 31 & 3-layer reinforcement & Circular I & 5 & $B / 3$ & $B / 2$ & $B$ & $2 B$ & $2 B$ & $2 B$ \\
\hline 32 & & & & & & & $3 B$ & $3 B$ & $3 B$ \\
\hline 33 & & & & & & & $4 B$ & $4 B$ & $4 B$ \\
\hline 34 & & & & & & & $2 B$ & $3 B$ & $4 B$ \\
\hline 35 & & & & & & & $3 B$ & $3 B$ & $4 B$ \\
\hline 36 & & & & & & $1.5 B$ & $2 B$ & $2 B$ & $2 B$ \\
\hline 37 & & & & & & & $3 B$ & $3 B$ & $3 B$ \\
\hline 38 & & & & & & & $4 B$ & $4 B$ & $4 B$ \\
\hline
\end{tabular}


Table 1 (continued)

\begin{tabular}{|c|c|c|c|c|c|c|c|c|c|}
\hline \multirow[t]{3}{*}{ No. } & \multirow[t]{3}{*}{ Model } & \multicolumn{2}{|l|}{ Foundation } & \multicolumn{6}{|c|}{ Reinforcement } \\
\hline & & \multirow[t]{2}{*}{ Shape } & \multirow{2}{*}{$\begin{array}{l}\text { Width }(\mathrm{cm}) \\
B\end{array}$} & \multicolumn{3}{|c|}{ Depth $(\mathrm{cm})$} & \multicolumn{3}{|c|}{ Length (cm) } \\
\hline & & & & $D_{1}$ & $D_{2}$ & $D_{3}$ & $b_{1}$ & $b_{2}$ & $b_{3}$ \\
\hline 39 & & & & & & & $2 B$ & $3 B$ & $4 B$ \\
\hline 40 & & & & & & & $3 B$ & $3 B$ & $4 B$ \\
\hline 41 & & Circular 2 & 8 & & & $B$ & $2 B$ & $3 B$ & $4 B$ \\
\hline 42 & & Square & 5 & & & & & & \\
\hline 43 & & Rectangular & 10 & & & & & & \\
\hline
\end{tabular}

properties shown in Table 3 were either provided by the manufacturer or directly measured in the laboratory. Since geonets are commonly used as drains in lowpermeable soils, they are not designated to have high tensile strengths as that in geogrids or geotextiles which are primarily used as reinforcing elements. As explained previously, in this paper we studied if geonets, when used for drainage purposes, can have a secondary role by contributing to the bearing capacity of soil.

\section{Testing Setup}

\section{Container}

A steel container was built with internal dimensions of $60 \mathrm{~cm}$ (length) $\times 50 \mathrm{~cm}$ (height) $\times 50 \mathrm{~cm}$ (width). The container was made from 5 -mm-thick steel plates with a front face of 6-mm-thick glass sheet. In general, the container walls were designed

Table 2 Physical, chemical and mechanical parameters of the soil

\begin{tabular}{ll}
\hline Property (unit) & Value \\
\hline USCS classification & $\mathrm{CL}$ \\
Passing sieve No. $200(\%)$ & 90 \\
Plastic limit (PL) & 17 \\
Liquid limit (LL) & 35 \\
Water content $(\%)$ & 12 \\
Unit weight $\left(\mathrm{kN} / \mathrm{m}^{3}\right)$ & 13 \\
Specific gravity, $G_{\mathrm{s}}$ & 2.68 \\
Poisson's ratio, $\nu$ & 0.3 \\
Organic content $(\%)$ & 0.45 \\
pH & 7.9 \\
Calcium carbonate $(\%)$ & 7.5 \\
$C_{\mathrm{u}}(\mathrm{kPa})$ & 12 \\
$\phi_{\mathrm{u}}(\mathrm{deg}$.) & 23 \\
Modulus of elasticity $(\mathrm{kPa})$ & 750 \\
\hline
\end{tabular}


Table 3 Properties of the geonet

\begin{tabular}{ll}
\hline Property (unit) & Value \\
\hline Aperture size (cm) & $1.3 \times 0.8$ \\
Percent open area (\%) & 47 \\
Thickness $(\mathrm{mm})$ & 1.74 \\
Density $\left(\mathrm{g} / \mathrm{cm}^{3}\right)$ & 0.923 \\
Mass per unit area $\left(\mathrm{g} / \mathrm{m}^{2}\right)$ & 750 \\
Tensile strength $(\mathrm{kN} / \mathrm{m})$ & 5.4 \\
Longitudinal stiffness, EA $(\mathrm{kN})$ & 25
\end{tabular}

and built to show no lateral deformation during the sample preparation as well as throughout the loading period. Figure 2 shows a schematic view of the container.

\section{Loading Frame}

As illustrated in Fig. 2, a steel shaft was used to transfer the applied load to the footing. The shaft was bolted to a rigid steel plate which represented the footing in the physical model. The base plate was rigid enough to exhibit no deformation during the loading period. Two circular footings with different diameters $(B=5 \mathrm{~cm}$ and $B=8 \mathrm{~cm})$, one square footing (dimensions: $5 \mathrm{~cm} \times 5 \mathrm{~cm}$ ) and one rectangular footing (dimensions: $10 \mathrm{~cm} \times 5 \mathrm{~cm}$ ) were tested with different configurations of the reinforcement layers (see Table 1). A dial gage was attached to the loading shaft in order to accurately measure vertical deformations during the loading process. Details of the loading frame and the steel container are shown in Fig. 2.

Fig. 2 Schematic view of the testing setup used in the study

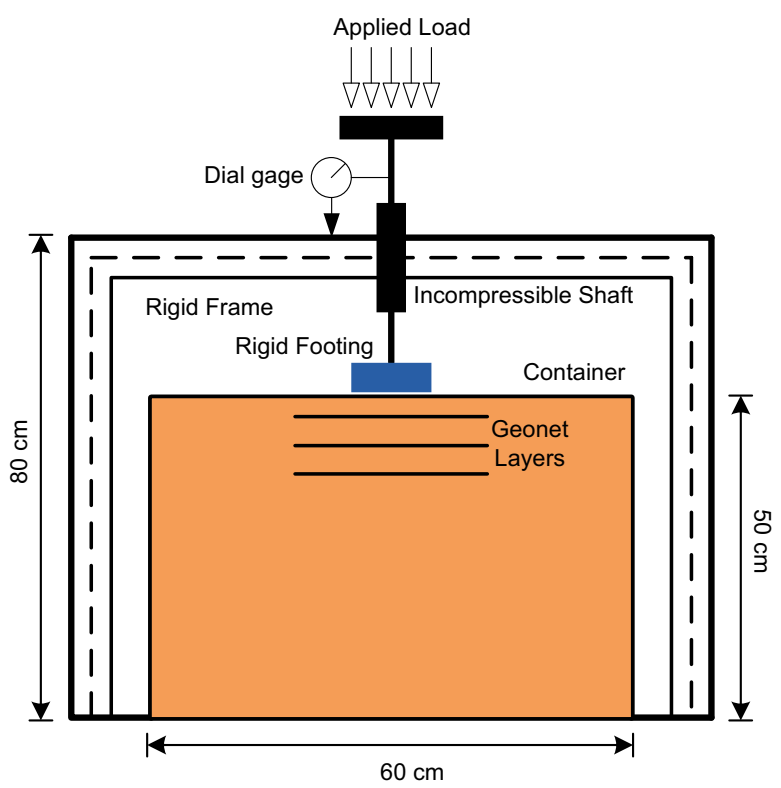




\section{Preparation of Foundation Soil}

After conducting various laboratory tests to determine different soil properties, the soil layers were placed in the container with the goal of achieving a unit weight of $13 \mathrm{kN} /$ $\mathrm{m}^{3}$. This unit weight corresponds to the measured value at the landfill site under natural conditions. The water content of the soil measured before placing the soil layers in the container was $12 \%$. The height of the container was divided into several layers with equal thickness and the required weight of soil for each layer was calculated based on the target unit weight. For the zone within the reinforcement layers, the weight of the required soil was calculated based on the spacing between the two subsequent layers. The soil was then carefully placed on top of the bottom geonet layer and was uniformly spread to create a leveled bed for the next geonet layer. Since the container had a front face of glass sheet, the thickness of the soil layers and the elevation of the geonet layers were checked after placement. After placing each layer, multiple soil samples were taken and tested to make sure the final unit weight and water content fall within the specified range. Since the tests were conducted in a temperature-controlled lab, no or minimal change in the water content during the tests was expected. Moreover, the unit weight of the soil measured before and after the tests showed no change in the unit weight during the tests. Multiple readings of the soil strength were conducted using a vane shear device and the average of readings was used in the numerical simulation. For the models including reinforcements, the geonet layers with different numbers, lengths, and depths were placed to simulate the cases listed in Table 1.

Once the footing was placed on top of the foundation soil, the loading procedure was carried out using static weights incrementally. The loading increments were applied in such a manner to avoid any impact, eccentricity or fluctuation. After applying each loading increment, the deformation was monitored until no further deformation was observed for more than $15 \mathrm{~min}$. Once the deformation became constant, the final deformation value was recorded for that loading increment and then, the next loading increment was added. Adding loading increments continued until the settlement exceeded $10 \%$ of the width of the footing (i.e., the criterion used to determine the ultimate bearing pressure in this study).

\section{Numerical Simulation}

In addition to the experimental tests, two-dimensional FE numerical simulations were performed using Plaxis. To minimize errors associated with the use of two-dimensional models for three-dimensional problems, the numerical simulations were only carried out for the circular footing by taking advantage of the axisymmetric geometry of this model. The axisymmetric numerical model can reasonably represent the threedimensional circular footing model. The dimensions of the FE model were defined identical to those of the equivalent physical model. The left and right boundaries were only permitted to move vertically and the bottom of the model was constrained against both horizontal and vertical movements. The foundation soil was modeled using the Mohr-Coulomb model using the parameters shown in Table 2. The geonet was modeled using tension elements with an axial stiffness, EA, of $25 \mathrm{kN} / \mathrm{m}$. An interface coefficient of 0.67 was used for the soil-geonet interface. The footing was modeled 
using linear-elastic plate elements with a very large elasticity modulus to represent a rigid footing. A uniform pressure of $P=200 \mathrm{kPa}$ was applied on the rigid footing. The applied pressure was equivalent to the ultimate load used in the experimental procedure. The model mesh was generated using 15-node triangular elements. An overall mesh size of medium was used for the model and the mesh size was locally refined around the loading surface as well as adjacent to the reinforcement layers. The final model included 1275 triangular elements. Sensitivity analysis was performed to make sure that an optimal mesh size was selected for the FE model.

Four numerical models were built: unreinforced, one-layer reinforcement, two-layer reinforcement, and three-layer reinforcement models. For the one-layer model, the length and depth are $b_{1}=3 B$ and $D=B / 3$, respectively. In the two-layer reinforcement model, two layers of $b_{1}=2 B$ and $b_{2}=4 B$ are modeled at the depth of $D_{1}=B / 3$ and $D_{2}=B /$ 2. For the three-layer reinforcement model, three layers of reinforcements with the length of $b_{1}=3 B$ and $b_{2}=3 B$ and $b_{3}=4 B$ were placed at the depth of $D_{1}=B / 3, D_{2}=B / 2$, and $D_{3}=\mathrm{B}$.

\section{Experimental Test Results}

The results from the experimental tests are presented in the subsequent sections. To interpret the test results and to determine the bearing capacity of reinforced soils, different failure criteria, introduced in the literature [31-33], can be employed. Some studies take the peak pressure of the bearing pressure-deformation curve corresponding to the ultimate bearing capacity while several researchers use the bearing pressure corresponding to settlement equal to $10 \%$ of the footing width [34-36]. In this research, the later definition is employed for the failure criterion. To quantify the bearing capacity improvement due to the geonet reinforcement, Bearing Capacity Ratio (BCR) is defined as the ratio of the soil pressure at the failure point for the reinforced soil to that in the unreinforced model.

The paper presents the results for the model-scale tests which were conducted. Similar footing shapes and sizes, as those used in the current study, have been employed in several similar laboratory model tests $[8,18,37,38]$. It should be noted that the scale effect should be taken into consideration for using results from small-scale laboratory models to simulate the response of full-scale reinforced foundation soil. Scaling the results obtained from the model tests is beyond the scope of the current study and further discussion about potential scale effects can be found in literature [21, 39-41].

\section{Test Results for Unreinforced Model}

As shown in Table 2, the tested clay is very weak and the bearing capacity of the soil without reinforcement is too low. Figure 3 shows the settlement versus bearing pressure for the unreinforced model for a circular footing with $B=5 \mathrm{~cm}$. As mentioned previously, the bearing pressure corresponding to a settlement equal to $10 \%$ of the footing width was used to determine BCR in this study. The experimental test results in Fig. 3 show that $5 \mathrm{~mm}$ settlement (i.e., $10 \%$ of the footing width) occurred at the bearing pressure of $13 \mathrm{kPa}$. This value is used in the next sections to calculate BCR for the reinforced models. 


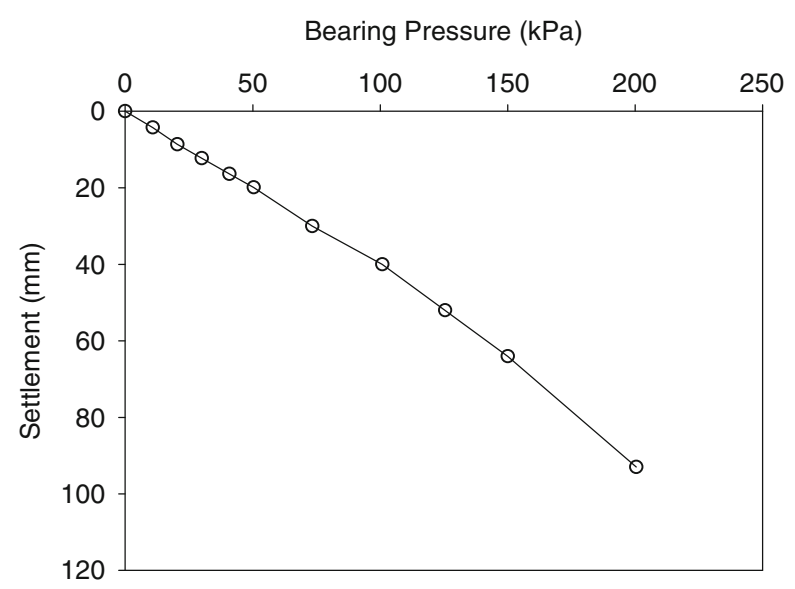

Fig. 3 Bearing pressure versus settlement for the unreinforced base model (circular footing, $B=5 \mathrm{~cm}$ )

\section{Effect of Depth and Length of Reinforcement}

To study the effect of reinforcement depth and length on BCR, 16 tests were performed on the single-layer reinforced models with a circular footing of $5 \mathrm{~cm}$ diameter. Four different lengths of the first reinforcement layer $\left(b_{1}=B, 2 B, 3 B\right.$, and $\left.4 B\right)$ and four different depths of the reinforcement layer $\left(D_{1}=B / 3, B / 2, B\right.$, and $\left.1.5 B\right)$ were examined.

Figure 4 shows the test results for the single-layer reinforcement model. Figure 4 illustrates the effect of reinforcement length on bearing capacity for four different depths of the reinforcement layer. The bearing capacity increases as the length of reinforcement increases. In similar fashion, BCR shows the largest improvement when the first layer of reinforcement is placed at the depth of $B / 3$. As shown, for the same depth of reinforcement, BCR increases with a longer reinforcement. Alternatively, the

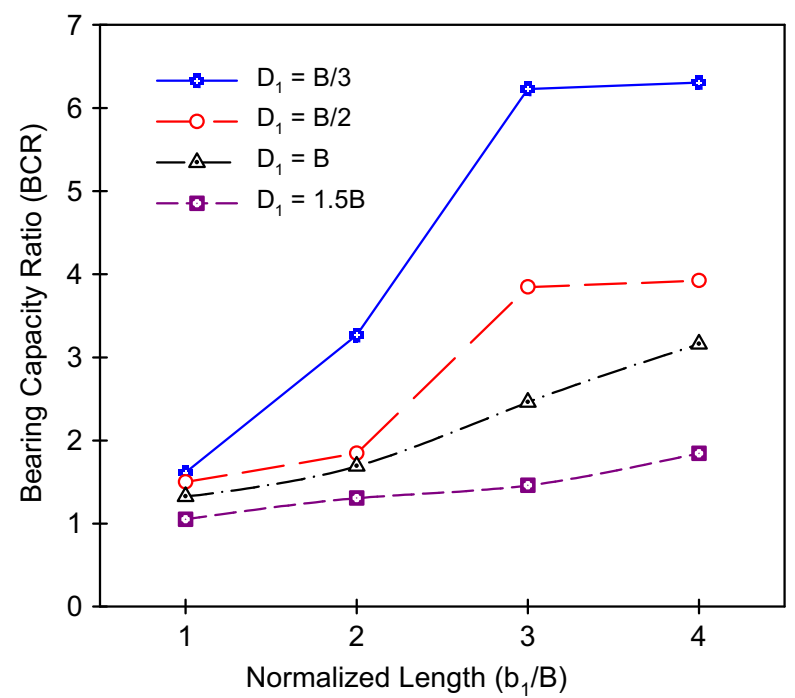

Fig. 4 Bearing capacity ratio versus normalized length of reinforcement in the single-layer reinforcement model 
results shown in Fig. 4 can be used to conclude that for a given length of reinforcement, a shallower reinforcement provides a higher BCR. It can be observed that BCR significantly increases in the model until $b_{1}=3 B$ but BCR increases further only for deeper geonet installations (e.g., $D_{1}=\mathrm{B}$ and 1.5B). This observation can suggest that there is an effective load spread angle. For the single-layer reinforcement model, one can use Fig. 4 to conclude that the maximum improvement was $\mathrm{BCR}=6$ and happened with the depth of reinforcement being $D_{1}=B / 3$ and the length of reinforcement being $b_{1}=3 B$.

\section{Effect of Spacing Between Reinforcement Layers}

The effect of spacing between reinforcement layers was investigated by performing a total of 20 tests with the 5-cm diameter circular footing on the two- and three-layer reinforcement models. Figures 5 and 6 show $\mathrm{BCR}$ versus $\mathrm{D}_{2}$ and $\mathrm{D}_{3}$ for the two- and three-layer reinforcement models, respectively.

For all the two-layer reinforcement models tested in this part, the first reinforcement layer was placed at $D_{1}=B / 3$ and the depth of the second layer was varied. The results shown in Fig. 5 indicate that maximum $\mathrm{BCR}$ occurred at $D_{2} / \mathrm{B}=0.5$ in these models. The highest improvement in the bearing capacity was observed in the model with two equally long reinforcements of $b_{1}=b_{2}=2 B$. The BCR value for this model was 4.5 . It is noteworthy to mention that increasing the length of reinforcement more than $2 B$ did not noticeably improve the performance of the reinforced foundation soil.

For all the three-layer reinforcement models tested in this part, the first and second reinforcement layers were placed at $D_{1}=B / 3$ and $D_{2}=B / 2$, respectively, and the depth of the third layer was varied. Figure 6 shows that the maximum BCR among the three-layer reinforcement models occurred at $D_{3} / B=1.0$. The model with $b_{1}=b_{2}=3 B$ and $b_{3}=4 B$ resulted in a BCR of 6.1 which was the highest among the others.

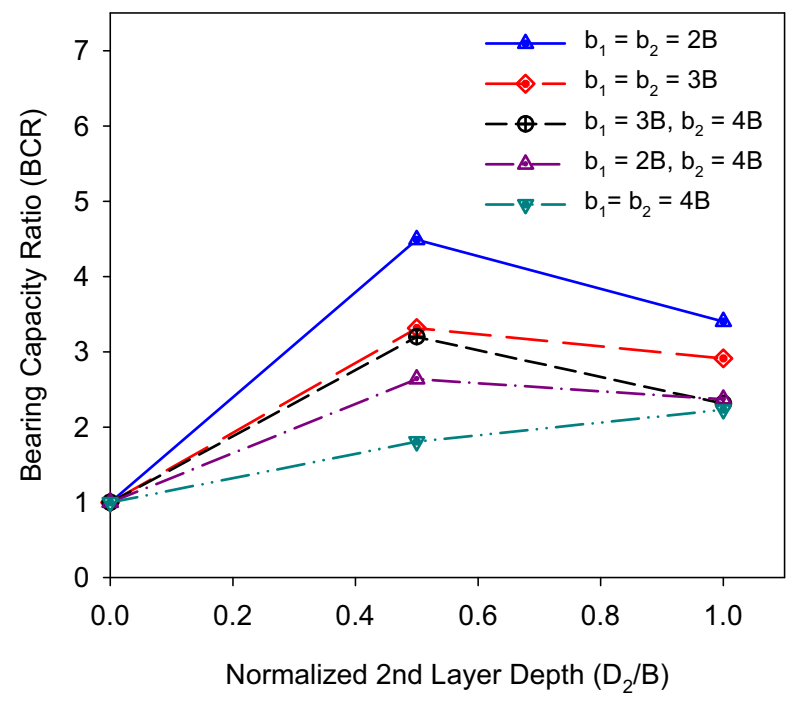

Fig. 5 Bearing capacity ratio versus normalized depth of the second reinforcement layer in the two-layer reinforcement model 


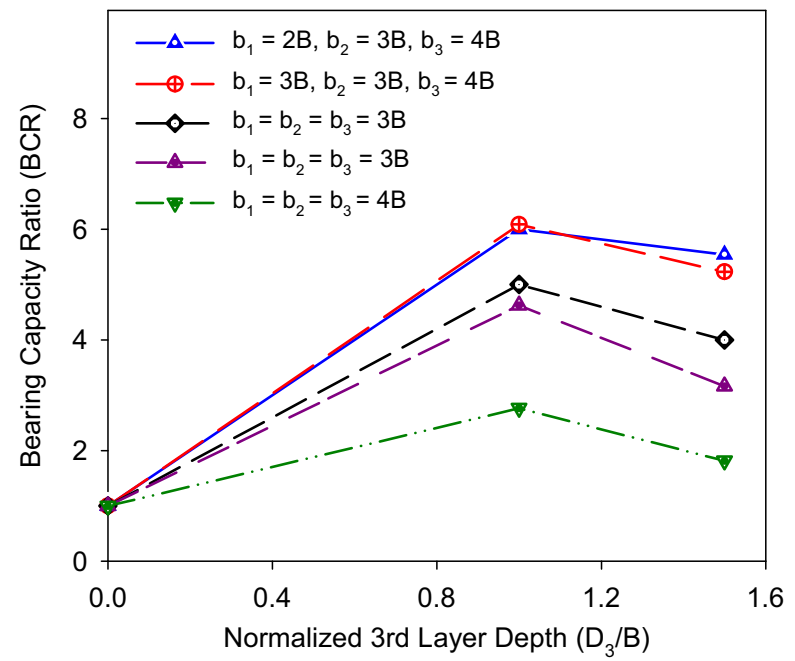

Fig. 6 Bearing capacity ratio versus normalized depth of the third reinforcement layer in the three-layer reinforcement model

\section{Effect of Footing Shape}

Four different footing shapes were tested to examine the effect of footing shape on bearing capacity and settlement of the foundation soil. The tested shapes were two circular footings $(B=5 \mathrm{~cm}$ and $B=8 \mathrm{~cm})$, one square footing $(5 \mathrm{~cm} \times 5 \mathrm{~cm})$ and one rectangular footing $(10 \mathrm{~cm} \times 5 \mathrm{~cm})$. The effect of footing shape on the bearing capacity was investigated for both the unreinforced and three-layer reinforcement models. For all the reinforced models, the depths and lengths of the first, second, and third reinforcement layers were kept constant at $D_{1}=B / 3, D_{2}=B / 2$, and $D_{3}=B$, and $b_{1}=2 B$, $b_{2}=3 B$, and $b_{3}=4 B$.

Bearing pressure versus normalized settlement $(S / B)$ for different footing shapes are shown in Figs. 7 and 8 for the unreinforced and reinforced models, respectively. As shown, the model with a rectangular footing showed the least settlement. Table 4 shows the bearing pressure at failure for the unreinforced soil, $q_{\mathrm{o}}$, and the bearing pressure at failure for the reinforced soil, $q_{1}$, for each footing shape. It can be concluded that the rectangular, square, and circular foundations show the least settlement, in that order from small to large settlement. To quantify the impact of the geonet reinforcement on bearing capacity, BCR values for the different footing shapes are also presented in this table. Among the footing types which were tested, the square footing was the most effective shape of footing with a $\mathrm{BCR}=7.6$.

\section{Numerical Modeling Results}

Two-dimensional axisymmetric FE modeling was performed for the 5-cm diameter circular footing without reinforcement, and also with one, two, and three layers of 


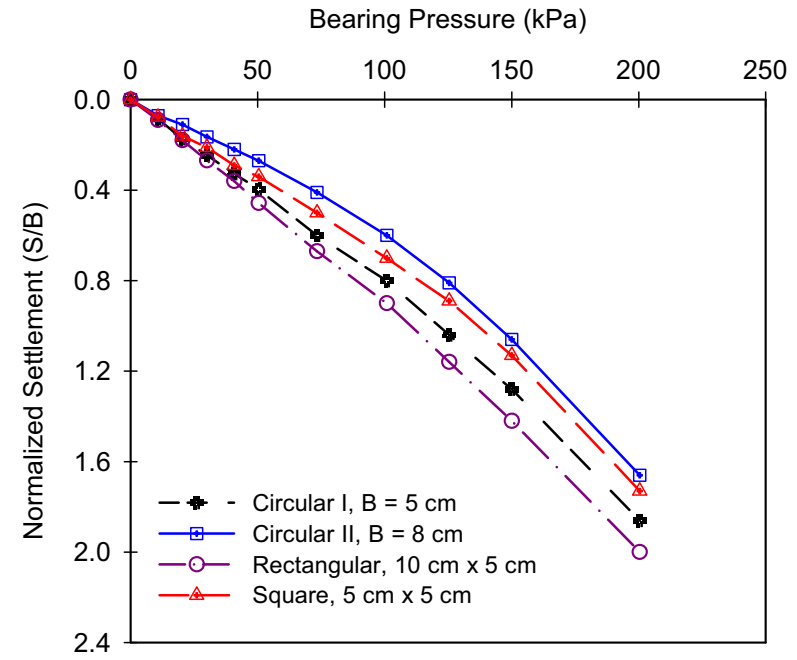

Fig. 7 Bearing pressure versus normalized settlement (S/B) for different footing shapes in the unreinforced model

geonet reinforcement. Figure 9 depicts settlement versus depth for the unreinforced model. As shown, the container boundaries are far enough to have no interference with the induced deformation in the model.

Contours of shear stresses for four different models are shown in Fig. 10. The stress plots show that the geonet reinforcements reduce the depth and lateral extension of the

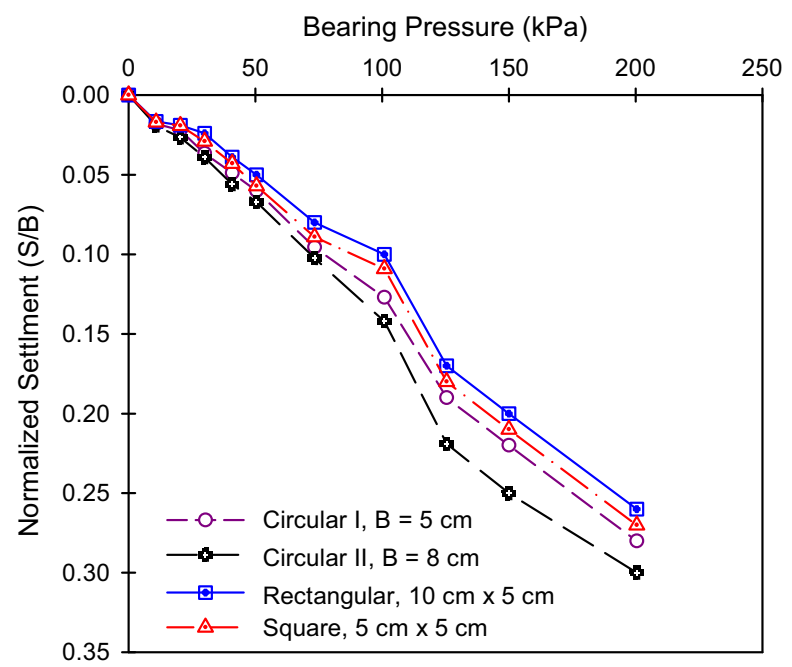

Fig. 8 Bearing pressure versus normalized settlement (S/B) for different footing shapes with three layers of reinforcement 
Table 4 Variation of BCR for different footing shapes with three reinforcement layers

\begin{tabular}{llll}
\hline Type of footing & $q_{\mathrm{o}}(\mathrm{kPa})$ & $q_{1}(\mathrm{kPa})$ & $\mathrm{BCR}$ \\
\hline Circular I, $B=5 \mathrm{~cm}$ & 2 & 12 & 6.0 \\
Circular II, $B=8 \mathrm{~cm}$ & 1.9 & 12.5 & 6.6 \\
Square, $5 \mathrm{~cm} \times 5 \mathrm{~cm}$ & 2.1 & 15.9 & 7.6 \\
Rectangular, $10 \mathrm{~cm} \times 5 \mathrm{~cm}$ & 2.3 & 16.4 & 7.1 \\
\hline
\end{tabular}

stress bulb in the foundation soil. Moreover, the mechanism of load transfer to the geonet layers can be seen in Fig. 10 where the shear stress in the soil significantly decreases below each geonet layer. The shear stress reduction in the soil is more pronounced when the geonet layers are used with optimum depth and length. As it can be observed, expansion of the shear stress bulb beneath the foundation is directly affected by the depth of the geonet layers. Figure 11 shows axial forces along the length of the reinforcement layers obtained from the FE simulations for the one-, two-, and three-layer reinforced models. As the number of layers increases, the load is distributed among the layers. In each model, the most bottom layer carries the highest load beneath the center of the footing.

The numerical modeling results were compared with those obtained from the experimental tests for the one-, two-, and three-layer reinforcement models. As demonstrated in Fig. 12, very good agreement was observed between the results from experimental testing and numerical modeling. As shown in Fig. 3, the

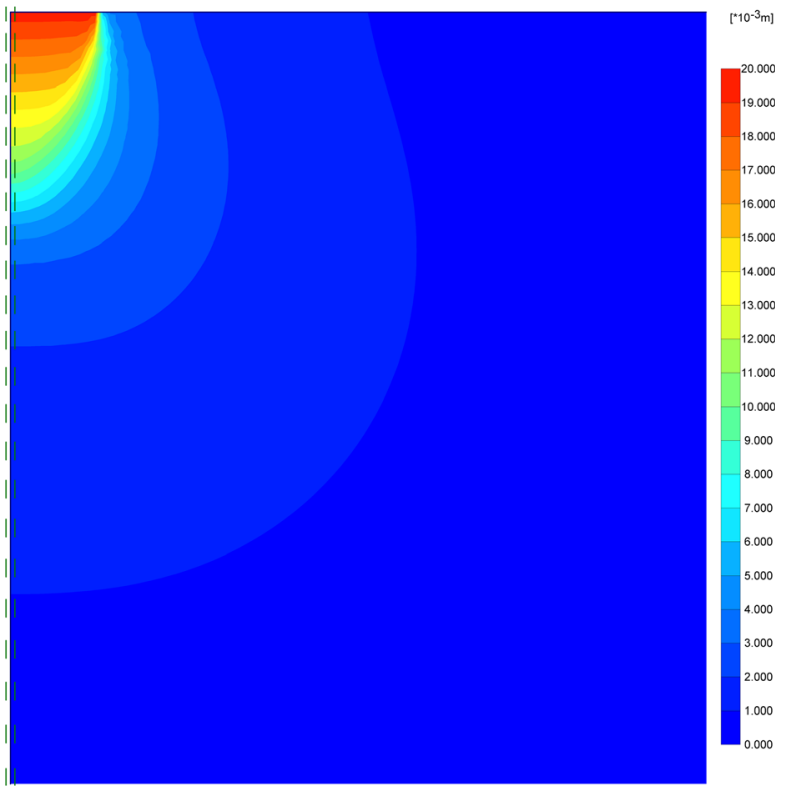

Fig. 9 Settlement contours with the contact pressure of $200 \mathrm{kPa}$ 
(a)

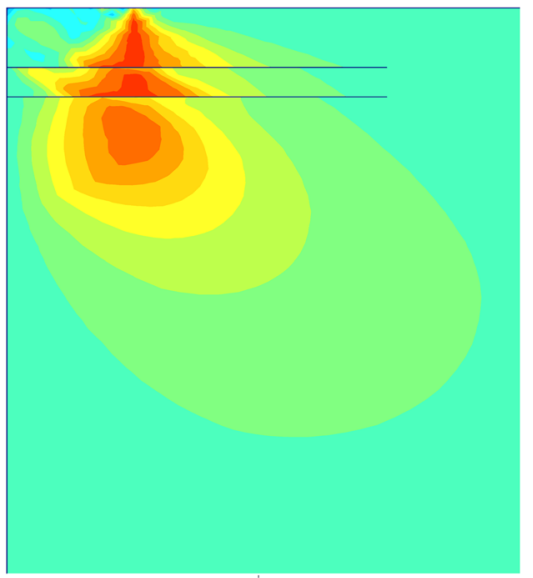

(c)

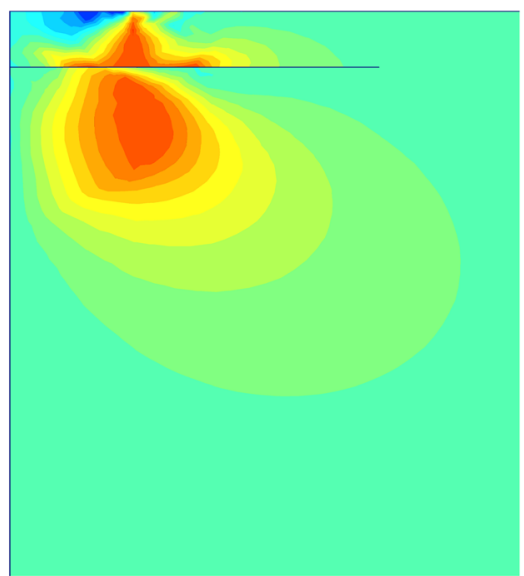

(b)

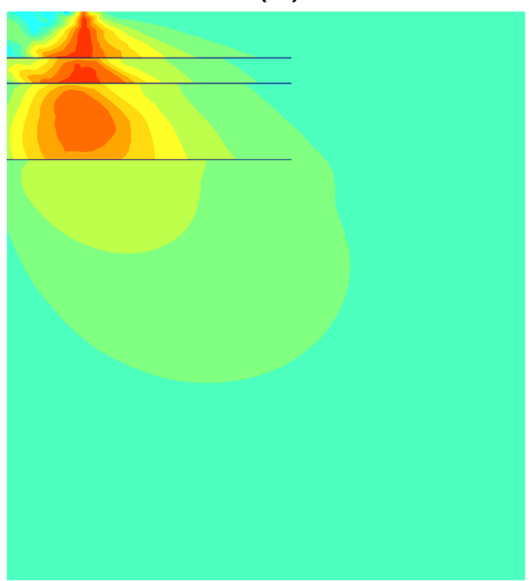

(d)

$\left[\mathrm{kN} / \mathrm{m}^{2}\right]$

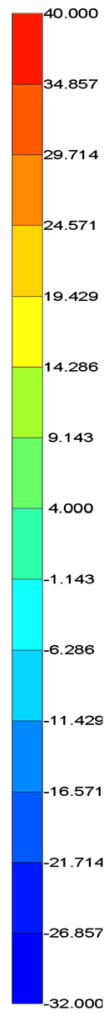

Fig. 10 Contours of shear stresses for: a unreinforced model, b one-layer reinforcement $\mathbf{c}$ two-layer reinforcement $\mathbf{d}$ three-layer reinforcement

bearing pressure for the unreinforced model with 5 -cm diameter circular footing was experimentally measured to be $13 \mathrm{kPa}$ at $5 \mathrm{~mm}$ settlement (i.e., $10 \%$
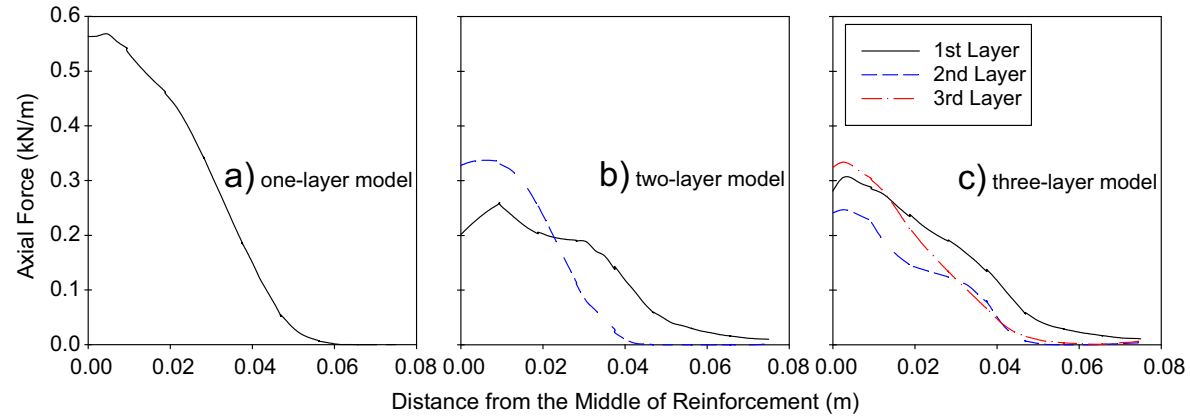

Fig. 11 Axial force developed in the reinforcement layers obtained from the numerical modeling, a one-layer model, b two-layer model, c three-layer model 


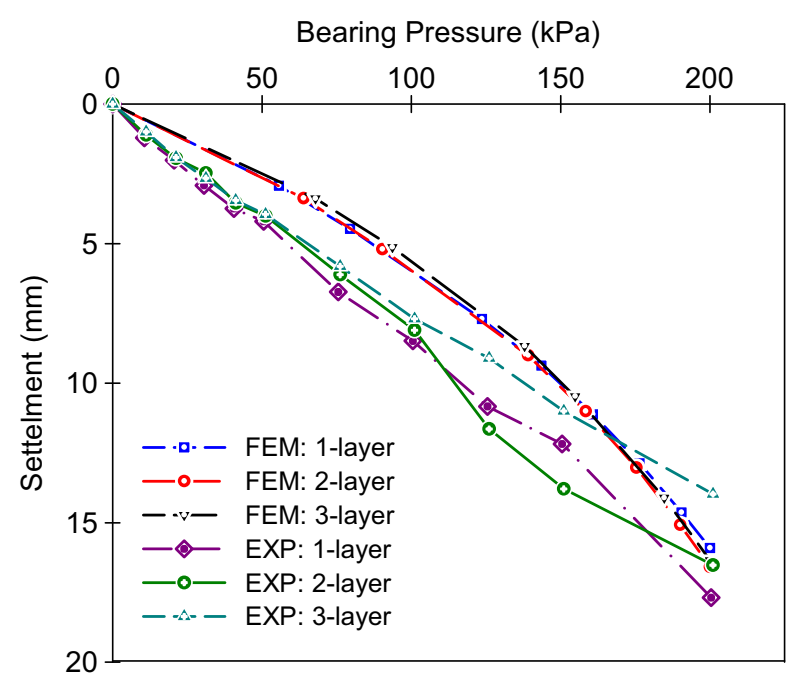

Fig. 12 Comparison of numerical modeling with experimental test results for different number of reinforcement layers

footing width). For the same footing with three reinforcement layers (Fig. 12), the experimental test resulted in $\mathrm{BCR}$ of 6.0 while the numerical modeling showed BCR of 6.6 .

\section{Conclusions}

Geonets are commonly used to facilitate drainage in low-permeable soils. This study investigated if geonets, when used as draining element, can also have a secondary function and improve the bearing capacity of low-compacted soft clay. Extensive experimental tests and numerical modeling were carried out to study the effect of various parameters as pertain to the footing (i.e., shape and size) and the geonet reinforcement (i.e., number of layers, length, spacing and depth of the first layer). While it is commonly recommended to replace such soft soil with engineered fill material, when needed for some particular applications, this study showed that the geonet reinforcement can significantly improve the bearing capacity of the soft clayey soil which was tested. As expected, using a higher number of reinforcement layers increased the bearing capacity.

To quantify the contribution of geonet reinforcement to the bearing capacity, Bearing Capacity Ratio (BCR) was defined as the ratio between the bearing pressure at failure for the reinforced model to that from the unreinforced soil. From the experimental tests and numerical modeling results, the following conclusions can be drawn:

- The most effective depths of the first, second, and third reinforcement layered were found to be $B / 3, B / 2$, and $B$, respectively.

- For the single-layer model, reinforcement length of $b=3 B$ is recommended at the optimum installation depth. The numerical modeling results showed that this length 
assures the mobilization of tension in the reinforcements. BCR did not significantly increase with longer reinforcements.

- For the two- and three-layer models, the optimum length of reinforcements was found to be $2 B$.

- Among different footing shapes which were tested, the square footing showed the highest bearing capacity improvement with a BCR of 7.6.

- This study showed that the geonet reinforcement can improve the bearing capacity of low-compacted soft clay up to six times more than its natural condition.

\section{References}

1. Koerner, R.M., Hwu, B.-L., Wayne, M.H.: Soft soil stabilization designs using geosynthetics. Geotext. Geomembr. 6, 33-51 (1987)

2. Lackner, C., Bergado, D., Semprich, S.: Prestressed reinforced soil by geosynthetics - concept and experimental investigations. Geotext. Geomembr. 37, 109-123 (2013)

3. Shivashankar, R., Jayaraj, J.: Effects of prestressing the reinforcement on the behavior of reinforced granular beds overlying weak soil. Geotext. Geomembr. 42, 69-75 (2013)

4. Chaiyaput, S., Bergado, D., Artidteang, S.: Measured and simulated results of a Kenaf Limited Life Geosynthetics (LLGs) reinforced test embankment on soft clay. Geotext. Geomembr. 42, 39-47 (2014)

5. Yamamoto, K., Otani, J.: Bearing capacity and failure mechanism of reinforced foundations based on rigid-plastic finite element formulation. Geotext. Geomembr. 20, 367-393 (2002)

6. Patra, C., Das, B., Atalar, C.: Bearing capacity of embedded strip foundation on geogrid-reinforced sand. Geotext. Geomembr. 23, 454-462 (2005)

7. Patra, C., Das, B., Bhoi, M., Shin, E.: Eccentrically loaded strip foundation on geogrid-reinforced sand. Geotext. Geomembr. 24, 254-259 (2006)

8. Lovisa, J., Shukla, S.K., Sivakugan, N.: Behaviour of prestressed geotextile-reinforced sand bed supporting a loaded circular footing. Geotext. Geomembr. 28, 23-32 (2010)

9. Plé, O., Lê, T.: Effect of polypropylene fiber-reinforcement on the mechanical behavior of silty clay. Geotext. Geomembr. 32, 111-116 (2012)

10. Sari, K., Chai, J.: Self healing capacity of geosynthetic clay liners and influencing factors. Geotext. Geomembr. 41, 64-71 (2013)

11. Alamshahi, S., Hataf, N.: Bearing capacity of strip footings on sand slopes reinforced with geogrid and grid-anchor. Geotext. Geomembr. 27, 217-226 (2009)

12. Bai, X.-H., Huang, X.-Z., Zhang, W.: Bearing capacity of square footing supported by a geobeltreinforced crushed stone cushion on soft soil. Geotext. Geomembr. 38, 37-42 (2013)

13. Boushehrian, A., Hataf, N., Ghahramani, A.: Modeling of the cyclic behavior of shallow foundations resting on geomesh and grid-anchor reinforced sand. Geotext. Geomembr. 29, 242-248 (2011)

14. Latha, G.M., Somwanshi, A.: Bearing capacity of square footings on geosynthetic reinforced sand. Geotext. Geomembr. 27, 281-294 (2009)

15. Vinod, P., Bhaskar, A.B..., Sreehari, S.: Behaviour of a square model footing on loose sand reinforced with braided coir rope. Geotext. Geomembr. 27, 464 474 (2009)

16. Haeri, S., Noorzad, R., Oskoorouchi, A.: Effect of geotextile reinforcement on the mechanical behavior of sand. Geotext. Geomembr. 18, 385-402 (2000)

17. Ghosh, A., Ghosh, A., Bera, A.K.: Bearing capacity of square footing on pond ash reinforced with jutegeotextile. Geotext. Geomembr. 23, 144-173 (2005)

18. Basudhar, P., Saha, S., Deb, K.: Circular footings resting on geotextile-reinforced sand bed. Geotext. Geomembr. 25, 377-384 (2007)

19. Chen, Q., Abu-Farsakh, M., Sharma, R., Zhang, X.: Laboratory investigation of behavior of foundations on geosynthetic-reinforced clayey soil. Transp. Res. Record: J. Transp. Res. Board 2004, 28-38 (2007)

20. Laman, M., Yildiz, A.: Numerical studies of ring foundations on geogrid-reinforced sand. Geosynth. Int. 14(2), 52-64 (2007)

21. Abu-Farsakh, M., Chen, Q., Sharma, R., Zhang, X.: Large scale model footing tests on geogrid reinforced footing and marginal embankment soils. Geotech. Test. J. 31(5), 413-423 (2008) 
22. Maheshwari, P., Viladkar, M.: A mathematical model for beams on geosynthetic reinforced earth beds under strip loading. Appl. Math. Model. 33, 1803-1814 (2009)

23. Sharma, R., Chen, Q., Abu-Farsakh, M., Yoon, S.: Analytical modeling of geogrid reinforced soil foundation. Geotext. Geomembr. 27, 63-72 (2009)

24. Moghaddas Tafreshi, S.N., Dawson, A.: Comparison of bearing capacity of a strip footing on sand with geocell and with planar forms of geotextile reinforcement. Geotext. Geomembr. 28, 72-84 (2010)

25. Huang, C.C.: Settlement of footings on reinforced level sandy ground at peak footing loads. Geosynth. Int. 18(3), 124-136 (2011)

26. Moghaddas Tafreshi, S.N., Khalaj, O., Halvaee, M.: Experimental study of a shallow strip footing on geogrid-reinforced sand bed above a void. Geosynth. Int. 18(4), 178-195 (2011)

27. Rowe, K.R., Taechakumthorn, C.: Design of reinforced embankments on soft clay deposits considering the viscosity of both foundation and reinforcement. Geotext. Geomembr. 29, 448-461 (2011)

28. Diambra, A., Ibraim, E., Muir Wood, D., Russell, A.: Fibre reinforced sands: experiments and modelling. Geotext. Geomembr. 28, 238-250 (2010)

29. Ornek, M., Laman, M., Demir, A., Yildiz, A.: Prediction of bearing capacity of circular footings on soft clay stabilized with granular soil. Soils Found. 52, 69-80 (2012)

30. Brinkgreve, R.B.J., Broere, W., Waterman, D.: Plaxis 2D-version 8. Plaxis bv, Delft, The Netherlands (2006)

31. Villalobos, F.: Bearing capacity of skirted foundations in sand. VI Congreso Chileno de Geotecnia, Valparaiso (2007)

32. Veiskarami, M., Jahanandish, M., Ghahramani, A.: Prediction of the bearing capacity and load-displacement behavior of shallow foundations by the stress-level-based ZEL method. Sci. Iran 18, 16-27 (2011)

33. Golmoghani-Ebrahimi, S., Rowshanzamir, M.: Experimental evaluation of bearing capacity of skirted footings. Civ. Eng. Archit. 1, 103-108 (2013)

34. Rea, C., Mitchell, J.K.: Sand reinforcement using paper grid cells, symposium on earth reinforcement, pp. 644-663. ASCE, Pittsburgh (1978)

35. Mahmoud, M., Abdrabbo, F.: Bearing capacity tests on strip footing resting on reinforced sand subgrades. Can. Geotech. J. 26, 154-159 (1989)

36. Gupta, R., Trivedi, A.: Bearing capacity and settlement of footing resting on confined loose silty sands. Electron. J. Geotech. Eng. 14, 1-4 (2009)

37. Mohamed, M.H.A.: Two dimensional experimental study for the behaviour of surface footings on unreinforced and reinforced sand beds overlying soft pockets. Geotext. Geomembr. 28, 589-596 (2010)

38. Moghaddas Tafreshi, S.N., Norouzi, A.H.: Bearing capacity of a square model footing on sand reinforced with shredded tire - an experimental investigation. Constr. Build. Mater. 35, 547-556 (2012)

39. Zhu, F., Clark, J.I., Phillips, R.: Scale effect of strip and circular footings resting on dense sand. J. Geotech. Geoenviron. Eng. 127(7), 613-621 (2001)

40. Cerato, A.B..., Lutenegger, A.J.: Scale effects of shallow foundation bearing capacity on granular material. J. Geotech. Geoenviron. Eng. 133(10), 1192-1202 (2007)

41. Ornek, M., Demir, A., Laman, M., Yildiz, A.M.: Numerical analysis of circular footings on natural ground stabilized with a granular fill. Acta Geotech. Slov. 1, 61-74 (2012) 